\title{
Eutanásia no Brasil: entre o Código Penal e a dignidade da pessoa humana
}

\section{Euthanasia in Brazil: between the Criminal Code and the dignity of the human person}

\section{GABRIELLA SOUSA DA SILVA BARBOSA}

Universidade Federal do Maranhão (Brasil) gssbarbosa@gmail.com

\section{FEDERICO LOSURDO*}

Universidade Federal do Maranhão (Brasil)

federico.losurdo@uniurb.it

Recebido/Received: 03.05.2017 / May 3 ${ }^{\text {rd }}, 2017$ Aprovado/Approved: 18.12.2017 / December 18 ${ }^{\text {th }}, 2017$

\section{Resumo}

No Brasil o atual Código Penal não tipifica a prática da eutanásia, alocando a conduta no art. 121, $\$ 1^{\circ}$, homicídio privilegiado. A "morte piedosa" começa a ser tratada pelas legislações e jurisprudência estrangeiras sem que o debate atinja maior destaque nos âmbitos legislativo e judiciário brasileiro. Entre a garantia da dignidade da pessoa humana, art. 10, III/CF-88, e a proteção à vida, art. 50, caput/CF-88, há uma nítida colisão de princípios. Tendo-se por base o direito comparado e por plano de fundo o julgamento

\section{Abstract}

The Brazilian Penal Code does not typify the practice of euthanasia, by qualifying this conduct as "manslaughter" (Article 121, first paragraph). The foreign legislation and Tribunals have started to discipline the "mercy killing", while such debate did not achieve prominence in the Brazilian Legislative and Judicial Branches. Indeed, between the guarantee of human dignity (art.10, cl. III, Brazilian Constitution) and the protection of the right to life (art. 50, caput, Brazilian Constitution) emerges a clear collision of principles. With a comparative approach and having as background the

Como citar esse artigo/How to cite this article: BARBOSA, Gabriella Souza da Silva; LOSURDO, Federico. Eutanásia no Brasil: entre o Código Penal e a dignidade da pessoa humana. Revista de Investigações Constitucionais, Curitiba, vol. 5, n. 2, p. 165-186, mai./ago. 2018. DOI: 10.5380/rinc.v5i2.52151.

"Mestranda do Programa de Pós-Graduação em Direito e Instituições do Sistema de Justiça da Universidade Federal do Maranhão - UFMA (São Luís-MA, Brasil). Graduada em Direito pela Unidade de Ensino Superior Dom Bosco - UNDB, São Luís-MA, Brasil. Email: gssbarbosa@gmail.com.

** Professor do Programa de Pós-Graduação em Direito e Instituições do Sistema de Justiça da Universidade Federal do Maranhão - UFMA (São Luís-MA, Brasil). PhD em Direito pela Universidade de Urbino (Itália), pela Universidad del Pais Vasco (Espanha), pela Università degli Studi di Catania (Itália) e pela Deutscher Akademischer Austauschdienst (Alemanha). Doutor em Direito pela Universidade de Urbino (Itália). Habilitado em Itália como Professor Associado de Direito Constitucional e Direito público. E-mail: federico.losurdo@uniurb.it. 
da ADI 3.510 pelo Supremo Tribunal Federal brasileiro e do Projeto de Lei n 236/12 - Novo Código Penal -, o qual tipifica a prática da eutanásia, analisa-se a possibilidade de não imputação de pena ao agente da eutanásia frente à interpretação constitucional.

Palavras-chave: eutanásia; vida; dignidade; novo Código Penal; Constituição Federal. decision in the ADI 3.510 of the Brazilian Supreme Court and the Project of Law n. 236/12 (the new Penal Code project), which typifies the practice of euthanasia, we analyze the possibility of not charging the euthanasia agent, in accordance with a constitutional interpretation.

Key-words: euthanasia; life; dignity; new Penal Code; Brazilian Constitution

\section{SUMÁRIO}

1. Introdução; 2. Conceituações eutanásicas; 3. Novo Código Penal e a tipificação da conduta de eutanásia no Brasil e no direito estrangeiro; 4. ADI 3.510 e a absolutização da vida; 5. Eutanásia: entre a dignidade da pessoa humana e o direito à vida sob a Constituição Federal de 1988; 6. Considerações Finais; 7. Referências.

\section{INTRODUÇÃO}

Consta do juramento de Hipócrates, raiz deontológico-moral da prática médica no mundo ocidental moderno, que "eu não darei qualquer droga fatal a uma pessoa, se me for solicitado, nem sugerirei o uso de qualquer uma deste tipo"1. Outrossim, diante das situações fáticas do exercício da medicina, não raros são os casos em que tais profissionais se veem entre os apelos de interrupção da vida de pacientes acometidos por dores incessantes, de familiares de enfermos que já perderam a esperança na recuperação destes ou mesmo de pessoas cujas condições atuais de saúde não lhes permitem um cotidiano condizente com suas aspirações e seus entendimentos quanto ao que seria uma vida digna.

É nesse diapasão em que surgem as deliberações quanto à eutanásia nos ordenamentos jurídicos contemporâneos. Prática comum desde os povos mais pretéritos $^{2}$, a "morte boa" - do grego eu, boa, e thanatos, morte - tem sido corriqueira em diversas culturas, variando suas concepções e motivações de acordo com a valoração da vida em cada comunidade ${ }^{3}$.

A eutanásia se fez presente no curso da história. Nas primeiras comunidades humanas percebem-se conceituações seletivas mais utilitaristas, em que a ausência da medicina e a necessidade de labuta constante para sobrevivência forçavam a

\footnotetext{
GOLDIM, José Roberto. Breve histórico da eutanásia. Núcleo Interinstitucional de Bioética - UFRGS, 2000. Disponível em: <https://www.ufrgs.br/bioetica/euthist.htm>. Acesso em: 13 de jul. de 2016. p. 1.

2 ASUA, Luis Jimenez de. Libertad de Amar y Derecho a Morrir - ensayos de un criminalista sobre eugenesia, eutanasia, endocrinologia. Madrid: Historia Nueva, 1929. p.122.

3 GUIMARÃES, Marcello Ovídio Lopes. Eutanásia - Novas considerações penais. 2008. 360 f. Tese (Doutorado do Departamento de Direito Penal, Medicina Forense e Criminologia) - Faculdade de Direito da Universidade de São Paulo, São Paulo, 2008. p. 14.
} 
eliminação dos idosos, doentes e deficientes. Quanto aos povos celtas se via a obrigação dos filhos em dar morte boa a seus pais, assim também, na Idade Média, podem-se citar os golpes de misericórdia aos feridos nas batalhas. Já na América do Sul era constantes as eliminações dos deficientes feitas pelos povos indígenas ${ }^{4}$.

Chega-se, nesse ínterim, aos interesses mais economicistas de eliminação de enfermos custosos ao Estado, ou mesmo práticas eugênicas de "purificação racial", como no exemplo nazista, erroneamente chamado de eutanásia ${ }^{5}$. Diante disso, o termo eutanásia ganhou uma amplitude de significações as quais dificultam um debate mais asséptico de sua possibilidade jurídica frente aos ordenamentos contemporâneos ${ }^{6}$.

Compreendida como ação omissiva ou comissiva de terceiro que cessa a vida de pacientes acometidos por graves doenças físicas ou psíquicas ${ }^{7}$, a eutanásia, enquanto morte piedosa, encontra como um dos principais obstáculos a sua legalização o status sacralizado do direito à vida, em uma reaproximação entre direito e moral nos ordenamentos pós-positivistas atuais ${ }^{8}$.

Ocorre que, diante do caráter fundamental do direito à vida e preservação desta nos casos de solicitação da prática eutanásica opõem-se não apenas a liberdade de escolha do paciente e/ou seus representantes legais, mas também a integridade física daquele que não mais suporta intervenções curativas em seu corpo, redundando primordialmente em atentado à dignidade do sujeito paciente enquanto pessoa humana.

É nesse diapasão que o presente trabalho busca compreender, frente ao ordenamento jurídico brasileiro e diante da colisão dos princípios supramencionados, a possibilidade de não imputação penal aos agentes da eutanásia à luz de uma interpretação conforme a Constituição Federal de 1988, sob a análise de ordenamentos estrangeiros, assim também das concepções sobre dignidade da pessoa humana e direito à vida do Supremo Tribunal Federal, em especial a ADI 3.510, além da tipificação da conduta presente no Projeto de Lei n²36/2012, o Projeto de Novo Código Penal.

\footnotetext{
4 ASUA, Luis Jimenez de. Libertad de Amar y Derecho a Morrir - ensayos de un criminalista sobre eugenesia, eutanasia, endocrinologia. Madrid: Historia Nueva, 1929. p. 122.

5 GUIMARÃES, Marcello Ovídio Lopes. Eutanásia - Novas considerações penais. 2008. 360 f. Tese (Doutorado do Departamento de Direito Penal, Medicina Forense e Criminologia) - Faculdade de Direito da Universidade de São Paulo, São Paulo, 2008. p. 14-15.

6 BARROSO, Luís Roberto; MARTEL, Letícia de Campos Velho. A morte como ela é: dignidade e autonomia individual no final da vida. Revista da Faculdade de Direito da Universidade Federal de Uberlândia, São Paulo, v. 34, n. 1, p. 235-274, 2010. p. 238.

7 GOLDIM, José Roberto. Breve histórico da eutanásia. Núcleo Interinstitucional de Bioética - UFRGS, 2000. Disponível em: <https://www.ufrgs.br/bioetica/euthist.htm>. Acesso em: 13 de jul. de 2016. p.1.

8 BARROSO, Luís Roberto; MARTEL, Letícia de Campos Velho. A morte como ela é: dignidade e autonomia individual no final da vida. Revista da Faculdade de Direito da Universidade Federal de Uberlândia, São Paulo, v. 34, n. 1, p. 235-274, 2010. p. 247.
} 


\section{CONCEITUAÇÕES EUTANÁSICAS}

A fim de delimitação das práticas analisadas no presente trabalho, importante que se distingam uma série de condutas comumente caracterizadas como eutanásicas, mas que com esta guardam apenas similitudes. Inicialmente, importa destacar que a chamada boa morte ou morte piedosa em nada se assemelha com as práticas eugênicas, a exemplo das levadas a cabo no regime nazista, responsáveis em parte pela negatividade contemporânea atribuída ao termo eutanásia, como rememora Marcello Ovidio Lopes Guimarães":

A despeito da nomenclatura, écerto que o programa de "eutanásia" nazista consistia em franca arbitrariedade, promovendo morte indiscriminada de portadores de deficiência físicas ou mentais, o que evidentemente não se confunde com a eutanásia propriamente dita. $^{10}$

Ora, a busca pela purificação racial através do genocídio nazista não se coaduna com a finalidade benigna da eutanásia, uma vez que nesta o que se busca é a eliminação da dor física ou psicológica do paciente, logo, o que motiva a conduta é a compaixão ${ }^{11}$, ao passo que naquela se ultrapassa o limite da benignidade, objetivando a eliminação étnica.

É nesse sentido que a prática nazista configura-se enquanto eugenia, termo introduzido por Francis Galton, em 1883 em seu livro Inquiries into human faculty and its development, sendo:

[...] uma doutrina hostil à reprodução dos "pobres e indolentes", pensada como um obstáculo ao aumento numérico dos "homens superiores" [...] propunha uma seleção artificial das novas gerações, demonstrando o caráter hereditário das qualidades intelectuais, fazendo total abstração dos fatores educativos e culturais na formação dos indivíduos. Assim, surge a idéia e a recomendação de medidas institucionais de intervenção corretora e compensadora tendo como finalidade restaurar a qualidade biológica do grupo pela introdução duma seleção artificial aplicada a seus membros. ${ }^{12}$

\footnotetext{
9 GUIMARÃES, Marcello Ovídio Lopes. Eutanásia - Novas considerações penais. 2008. 360 f. Tese (Doutorado do Departamento de Direito Penal, Medicina Forense e Criminologia) - Faculdade de Direito da Universidade de São Paulo, São Paulo, 2008. p. 14.

10 GUIMARÃES, Marcello Ovídio Lopes. Eutanásia - Novas considerações penais. 2008. 360 f. Tese (Doutorado do Departamento de Direito Penal, Medicina Forense e Criminologia) - Faculdade de Direito da Universidade de São Paulo, São Paulo, 2008. p. 14.

11 MARTIN, Leonard M. Eutanásia e Distanásia. In: COSTA, Sérgio Ibiapina; GARRAFA, Volnei; OSELKA, Gabriel. (Orgs). Iniciação à Bioética. Brasília: Conselho Federal de Medicina, 1998. p. 171-192. p. 183.

12 MENEGAT, Carla. Os pensadores que influenciaram a política de eugenia do nazismo. Revista A MARgem, Uberlândia, Minas Gerais, ano 1, n. 2, p. 66-73, jul./dez. 2008. p. 67.
} 
Eliminada, portanto, a alcunha eugênica, passa-se à análise mais detalhada das práticas relacionadas a uma morte por benignidade. Primeiramente, a fim de evitar confusões polissêmicas cabe precisar o entendimento hodierno da eutanásia, cujo aparecimento na história moderna é atribuído a Francis Bacon, 1623, em seu livro Historia vitae et mortis ${ }^{13}$.

Tomando por base os ensinamentos de Leonard M. Martin ${ }^{14}$ pode-se compreender a eutanásia como uma abreviação direta da vida do paciente com intenção eliminadora, por meio de ação ou omissão movida pela compaixão. Mais adiante, para o autor são quatro os elementos fundamentais para diferenciá-la das demais modalidades de abreviação da vida com as quais comumente é confundida. Sendo eles: o resultado provocado, a intenção ou motivação para praticar o ato, a natureza deste e as circunstâncias em que é praticado ${ }^{15}$.

Acima analisados a intenção de abreviar o sofrimento do paciente, assim como a natureza benigna da conduta ${ }^{16}$, restam apenas os outros dois elementos. Tem-se por resultado da conduta eutanásica a morte antecipada de modo suave e sem dor, a chamada morte doce, cujo "grande objetivo é proteger a dignidade da pessoa"17. É nesse sentido que a mesma se distingue da chamada distanásia, uma vez que esta se configura pela medicalização constante do paciente em vias de morrer, o uso exacerbado das, cada vez mais crescentes, tecnologias médicas, de modo a prolongar o quadro terminal de pacientes sem cura ${ }^{18}$.

Importante ressaltar que a distanásia é prática comum do atual paradigma médico - técnico-científico e comercial-empresarial ${ }^{19}$-, a qual vem sendo aplicada de modo contínuo nas Unidades de Terapia Intensiva (UTIs) do país, posto que se preza pela continuidade da vida a todo custo diante do avanço tecnológico e dos ganhos empresariais do aumento do uso de tais tecnologias em equipamentos ${ }^{20}$.

13 GOLDIM, José Roberto. Breve histórico da eutanásia. Núcleo Interinstitucional de Bioética - UFRGS, 2000. Disponível em: <https://www.ufrgs.br/bioetica/euthist.htm>. Acesso em: 13 de jul. de 2016. p.1.

14 MARTIN, Leonard M. Eutanásia e Distanásia. In: COSTA, Sérgio Ibiapina; GARRAFA, Volnei; OSELKA, Gabriel. (Orgs). Iniciação à Bioética. Brasília: Conselho Federal de Medicina, 1998. p. 183.

15 MARTIN, Leonard M. Eutanásia e Distanásia. In: COSTA, Sérgio Ibiapina; GARRAFA, Volnei; OSELKA, Gabriel. (Orgs). Iniciação à Bioética. Brasília: Conselho Federal de Medicina, 1998. p. 180.

16 DWORKIN, Ronald. Domínio da Vida - Aborto, eutanásia e liberdades individuais. São Paulo: Martins Fontes, 2003 p. 1.

17 MARTIN, Leonard M. Eutanásia e Distanásia. In: COSTA, Sérgio Ibiapina; GARRAFA, Volnei; OSELKA, Gabriel. (Orgs). Iniciação à Bioética. Brasília: Conselho Federal de Medicina, 1998. p. 181.

18 DINIZ, Débora; COSTA, Sérgio. Morrer com dignidade: um direito fundamental. In: CAMARANO, Ana Amélia. Os Novos Idosos Brasileiros: Muito Além dos 60. Rio de Janeiro: IPEA, 2004. p. 130.

19 MARTIN, Leonard M. Eutanásia e Distanásia. In: COSTA, Sérgio Ibiapina; GARRAFA, Volnei; OSELKA, Gabriel. (Orgs). Iniciação à Bioética. Brasília: Conselho Federal de Medicina, 1998. p. 187

20 SANTANA, Júlio César Batista; RIGUEIRA, Ana Cláudia de Melo; DUTRA, Bianca Santana. Distanásia: reflexões sobre até quando prolongar a vida em uma Unidade de Terapia Intensiva na percepção dos enfermeiros. Revista Bioethikos, Minas Gerais, Centro Universitário São Camilo, ano 4, vol. 4, 2010. p. 402-411. 
Nesse sentido, clarificam o conceito os autores supracitados:

A distanásia trata-se de um neologismo de origem grega: o prefixo dys significa ato defeituoso, afastamento e o sufixo thanatos designa morte. Na sua origem semântica, distanásia significa morte lenta, com muita dor ou prolongamento exagerado da agonia, do sofrimento e da morte de um paciente, não respeitando a dignidade do morrente. ${ }^{21}$

Quanto às circunstâncias em que se pratica a eutanásia, importante para os fins deste estudo a distinção entre a eutanásia ativa - cuja ação de terceiro ocasiona a morte - da modalidade passiva, alcançada pela omissão, assim também a chamada eutanásia indireta, cuja ação não objetivava a morte do paciente, sendo o resultado uma consequência ${ }^{22}$.

Do mesmo modo, cumpre destacar, a fins de análise quanto à autonomia do paciente, a diferença entre eutanásia voluntária, não-voluntária e involuntária. Segundo as lições de Terrance McConnell ${ }^{23}$, a primeira caracteriza-se pelo consentimento expresso e informado do paciente quanto ao desejo de abreviação de sua vida; a modalidade nãovoluntária, por sua vez, acontece quando não há o conhecimento da vontade do paciente, a exemplo de enfermos em estado de coma profundo, os quais nunca manifestaram sua vontade quanto à interrupção da vida em situações de enfermidade ou estado terminal; enquanto a involuntária é aquela realizada contra a vontade do paciente.

Por fim, cabe ainda o entendimento quanto à ortotanásia. Tal modalidade de morte piedosa diferencia-se das anteriores, uma vez que não atua de modo direto para interromper a vida, nem intenta o prolongamento da mesma, tal qual se observa na distanásia, mas pretende o oposto: respeitar o processo natural do viver e o curso da morte, aplicando ao paciente apenas medidas paliativas, a fim de amenizar os sintomas advindos deste processo, tornando o momento da morte mais humanizado possível àquele paciente ${ }^{24}$.

É nesse sentido que Luís Roberto Barroso e Letícia de Campos Velho Martel ${ }^{25}$ falam que a ortotanásia "Trata-se da morte em seu tempo adequado, não combati-

21 SANTANA, Júlio César Batista; RIGUEIRA, Ana Cláudia de Melo; DUTRA, Bianca Santana. Distanásia: reflexões sobre até quando prolongar a vida em uma Unidade de Terapia Intensiva na percepção dos enfermeiros. Revista Bioethikos, Minas Gerais, Centro Universitário São Camilo, ano 4, vol. 4, 2010. p. 403.

22 BARROSO, Luís Roberto; MARTEL, Letícia de Campos Velho. A morte como ela é: dignidade e autonomia individual no final da vida. Revista da Faculdade de Direito da Universidade Federal de Uberlândia, São Paulo, v. 34, n. 1, p. 235-274, 2010. p. 239.

23 MCCONNELL, Terrance. Inalienable rights: the limits of consent in medicine and the law. Oxford: Oxford University, 2000. p. 88.

24 MARTIN, Leonard M. Eutanásia e Distanásia. In: COSTA, Sérgio Ibiapina; GARRAFA, Volnei; OSELKA, Gabriel. (Orgs). Iniciação à Bioética. Brasília: Conselho Federal de Medicina, 1998. p. 190.

25 BARROSO, Luís Roberto; MARTEL, Letícia de Campos Velho. A morte como ela é: dignidade e autonomia individual no final da vida. Revista da Faculdade de Direito da Universidade Federal de Uberlândia, São Paulo, v. 34, n. 1, p. 235-274, 2010. p. 240. 
da com os métodos extraordinários e desproporcionais utilizados na distanásia, nem apressada por ação intencional externa, como na eutanásia".

\section{NOVO CÓDIGO PENAL BRASILEIRO E A TIPIFICAÇÃO DA CON- DUTA DE EUTANÁSIA NO BRASIL E NO DIREITO ESTRANGEIRO}

No Brasil, contrariando-se tendência recente de despenalização da prática do dito homicídio piedoso ou homicídio eutanásico, o atual Código Penal (Decreto-Lei 2.848/40) em nada explicita ou mesmo despenaliza a prática da morte por benignidade, alocando todas as condutas analisadas no item supra como sendo facetas de um mesmo crime, o homicídio tipificado no art. 121 do referido Código.

Ora, causa estranhamento o arrojo punitivo do Estado brasileiro no Código Penal atual quanto ao homicídio eutanásico em comparação ao código anterior - a Consolidação das Leis Penais de 1932 -, o qual repetiu as disposições de seu antecessor, Código Penal do Império, de 1890, que propunha em seu artigo 295, parágrafo 2:

[...] que se a morte resultar não da verificação de um mal mortal, mas sim por ter o ofendido deixado de observar o regime médico-higiênico reclamado pelo seu estado, a reprimenda cominada ao agente sofre aguda redução em relação ao homicídio simples, sendo graduada de dois a oito anos de prisão celular.

Inegável que no referido parágrafo aloca-se a eutanásia em sua forma omissiva. Outrossim, o mesmo diploma é explícito em seu artigo 24, quanto à não criminalidade e justificação da conduta criminosa nos casos em que "[...] acções ou omissões contrárias à lei penal que não forem commettidas com intenção criminosa, não resultarem de negligência, imprudência ou imperícia, não serão passíveis de pena".

Tal entendimento vê-se reforçado quando da combinação deste dispositivo com o artigo 32, parágrafo $1^{\circ}$ do mesmo Código Penal Imperial, que explicita que a conduta não será criminosa caso o crime tenha sido para evitar "mal maior", facilmente subsumindo-se à conduta do homicídio por piedade, quando o agente realiza o homicídio visando evitar a degradação psicológica e física de pacientes em estado de largo sofrimento.

Indubitável, portanto, que as mencionadas codificações penais antecessoras do atual Código Penal foram além da percepção deste quanto ao paradigma da benignidade presente em um homocídio piedoso. Nesse sentido, condizentes são as lições de Marcello Ovidio Lopes Guimarães ${ }^{26}$ :

26 GUIMARÃES, Marcello Ovídio Lopes. Eutanásia - Novas considerações penais. 2008. 360 f. Tese (Doutorado do Departamento de Direito Penal, Medicina Forense e Criminologia) - Faculdade de Direito da Universidade de São Paulo, São Paulo, 2008. p. 77. 
A possibilidade de se justificar uma conduta provocadora da morte, ligando-a a uma prática eutanásica, com base na interpretação do que consta da lei penal, foi, assim, reduzida ou inviabilizada. Antes, já poderia não ser aceitável uma interpretação nesse sentido, do ponto de vista cultural, mormente para a época em que vigoravam os códigos anteriores, ainda que a lei concedesse, em primeira análise, mais amplitude para a defesa de uma justificação nesses casos. Agora, ao contrário, mesmo que possa não haver um quase intransponível impedimento sócio-cultural (sic) como outrora, é a lei penal que, ao menos pelo seu texto expresso, não traz maior subsídio para uma justificação criminal da conduta eutanásica. ${ }^{27}$

Com a alteração da parte geral do atual Código Penal, Lei n 7.209/84, acrescentou-se a causa de diminuição de pena do homicídio privilegiado, artigo 121, parágrafo 1, cujo conteúdo vem sendo utilizado na prática jurídica para casos de homicídio eutanásico, uma vez que prevê a possibilidade de redução da pena pelo magistrado de um sexto a um terço, em casos de crimes praticados por motivo de relevante valor social ou moral.

Uma vez que a garantia dada ao agente da eutanásia não é a despenalização, mas sim a remota possibilidade de que o juiz entenda o homicídio piedoso enquanto homicídio privilegiado e apenas reduza a pena do autor, os profissionais de saúde no país acabam por temer as hipóteses de negligência caso não optem pelas reanimações ou medidas curativas de pacientes terminais, mesmo sem o consentimento dos mesmos, prolongando a vida com procedimentos distanásicos ${ }^{28}$.

Assim sendo, tanto a eutanásia quanto a ortotanásia - aí compreendida a limitação do tratamento constituiriam hipóteses de homicídio. [...] A existência de consentimento não produziria o efeito jurídico de salvaguardar o médico de uma persecução penal. Em suma: não haveria distinção entre o ato de não tratar um enfermo terminal segundo a sua própria vontade e o ato de intencionalmente abreviar-lhe a vida, também a seu pedido. [...] Essa postura legislativa e doutrinária pode produzir consequências graves, pois, ao oferecer o mesmo tratamento jurídico para situações distintas, o paradigma legal reforça condutas de obstinação terapêutica e acaba por promover a distanásia. Com isso, endossa um modelo médico paternalista, que se funda na autoridade do profissional da medicina sobre o paciente e descaracteriza a condição de sujeito do enfermo. ${ }^{29}$

27 GUIMARÃES, Marcello Ovídio Lopes. Eutanásia - Novas considerações penais. 2008. 360 f. Tese (Doutorado do Departamento de Direito Penal, Medicina Forense e Criminologia) - Faculdade de Direito da Universidade de São Paulo, São Paulo, 2008. p. 77.

28 SANTANA, Júlio César Batista; RIGUEIRA, Ana Cláudia de Melo; DUTRA, Bianca Santana. Distanásia: reflexões sobre até quando prolongar a vida em uma Unidade de Terapia Intensiva na percepção dos enfermeiros. Revista Bioethikos, Minas Gerais, Centro Universitário São Camilo, ano 4, vol. 4, 2010. p. 402-411.

29 BARROSO, Luís Roberto; MARTEL, Letícia de Campos Velho. A morte como ela é: dignidade e autonomia individual no final da vida. Revista da Faculdade de Direito da Universidade Federal de Uberlândia, São Paulo, v. 34, n. 1, p. 235-274, 2010. p. 8-9. 
Nesse diapasão, percebe-se que a opção legislativa brasileira vai de encontro a muitas legislações e jurisprudências estrangeiras, não apenas europeias, como também americanas. É de se destacar o exemplo uruguaio, considerado o primeiro país do mundo a legislar sobre o homicídio eutanásico, cujo Código Penal de 1934 trouxe em seu artigo 37 a exclusão de imputação de pena a agentes que cumpram três requisitos: ter antecedentes honráveis, ser realizado por motivo piedoso; e mediante reiteradas súplicas do sujeito passivo da conduta. ${ }^{30}$

Ainda, na América Latina emblemático o exemplo colombiano. Fortes eram os debates sobre a eutanásia no país desde 1979 com o Movimento pelo Direito a Morrer com Dignidade e com os constantes incentivos deste para a elaboração de testamentos vitais pela população - documentos em que o indivíduo deixa explícita sua vontade quanto ao uso ou não de terapias e ressuscitações em um futuro hipotético em que não possuam capacidade ou condições para expressar tal vontade - até que no ano de 1997 fora trazida à deliberação da Corte Constitucional Colombiana, pelo magistrado Carlos Gaviria, a confrontação entre o homicídio piedoso e o artigo 326 do código penal do país ${ }^{31}$.

Com uma vitória de seis votos a três, a Corte Constitucional Colombiana decidiu pela exclusão de penalidade aos médicos que praticassem a eutanásia em sua modalidade omissiva e voluntária, ou seja, aquela em que se retira ou não se usa o tratamento a pedido do paciente, a fim de lhe possibilitar uma morte digna ${ }^{32}$.

La Constitución no sólo protege la vida como un derecho sino que además la incorpora como un valor del ordenamiento, que implica competencias de intervención, e incluso deberes, para el Estado y para los particulares. La Carta no es neutra frente al valor vida sino que es un ordenamiento claramente en favor de él, opción política que tiene implicaciones, ya que comporta efectivamente un deber del Estado de proteger la vida. Sin embargo, tal y como la Corte ya lo mostró en anteriores decisiones, el Estado no puede pretender cumplir esa obligación desconociendo la autonomía y la dignidad de las propias personas. Por ello ha sido doctrina constante de esta Corporación que toda terapia debe contar con el consentimiento informado del paciente, quien puede entonces rehusar determinados tratamientos que objetivamente podrían prolongar la duración de su existencia biológica pero que él considera incompatibles con sus más hondas convicciones personales. Sólo el titular del derecho a la vida puede decidir hasta cuándo es ella deseable y compatible con la dignidad humana. Y si los derechos no son absolutos,

30 GOLDIM, José Roberto. Eutanásia - Uruguai. Núcleo Interinstitucional de Bioética - UFRGS, 1997. Disponível em: <https://www.ufrgs.br/bioetica/eutanuru.htm>. Acesso em: 13 de jul. de 2016. p.1.

31 GOLDIM, José Roberto. Eutanásia - Uruguai. Núcleo Interinstitucional de Bioética - UFRGS, 1997. Disponível em: <https://www.ufrgs.br/bioetica/eutanuru.htm>. Acesso em: 13 de jul. de 2016. p.1.

32 DINIZ, Débora. A despenalização da eutanásia passiva: o caso colombiano. SérieAnis, Brasília, n.13, Letras Livres, p. 1-3, 2000. p.1. 
tampoco lo es el deber de garantizarlos, que puede encontrar límites en la decisión de los individuos, respecto a aquellos asuntos que sólo a ellos les atañen..$^{33}$

Ainda na seara do direito comparado, muitos são os ordenamentos jurídicos contemporâneos a autorizar, ao menos a forma omissiva do homicídio piedoso. Na Holanda a legislação atual sobre o tema remonta de 1993, na qual a forma omissiva é fato atípico, enquanto a forma comissiva é excludente de ilicitude na conduta de homicídio, desde que observados os requisitos de: capacidade mental do doente - pessoas entre doze a dezesseis anos podem obter a eutanásia, desde que haja a concordância dos pais -; que o paciente tenha reiterado de modo voluntário seu pedido; e que esteja acometido por doença incurável com sofrimento agonizante atestado por um médico. A Bélgica adota a mesma linha holandesa desde 2002.

Na Espanha, o novo Código Penal despenaliza a eutanásia passiva e a ativa indireta, desde que presentes a vontade séria e inequívoca do paciente ${ }^{34}$. Já na China a prática está autorizada desde 1998, cabendo ao médico determina-la sob a única condição de terminalidade do paciente. Nos Estado Unidos, os estados da Califórnia, Oregon, Massachussets e Conecticut possibilitam as condutas omissivas ou de interrupção do suporte vital ${ }^{35}$.

Apesar destas revisões nas legislações ou mesmo em jurisprudências que passam a possibilitar o alcance da morte piedosa sem aplicação de pena a seus agentes, importante acrescentar que, segundo os apontamentos de Guilherme Gouvea Pícolo ${ }^{36}$ :

A corrente de pensamento dominante na legislação penal mundial é a do tratamento da eutanásia como homicídio privilegiado, tendo a pena reduzida e equiparada, como no caso da Argentina, à do crime correspondente ao de instigação e auxílio ao suicídio previsto em nossa legislação. É possível observar esta realidade no artigo 116 do Código Penal costa-riquenho e no artigo 157 do código peruano. Adotam este entendimento também Noruega, Polônia e Suíça. Outros países preferem tratar a eutanásia como um tipo penal próprio diferenciado do homicídio: é o que acontece em Cuba, na Áustria e na Grécia. Nestes casos, no entanto, o espírito da lei também é o de manter a conduta como crime, mas oferecendo um tratamento punitivo mais brando. ${ }^{37}$

33 COLOMBIA, Sentença C-239/97.

34 ARZAMENDI, José Luis de La Cuesta. A eutanásia no direito comparado. Revista Jurídica Consulex, São Paulo, ano V, n. 114, out. 2001. p. 15.

35 PÍCOLO, Guilherme Gouvêa. O direito de morrer: eutanásia, distanásia e ortotanásia no direito comparado. Revista Investidura, Florianópolis - Santa Catarina, ano 4, vol. 18, p. 16-21, mar./abr. 2012. p. 17.

36 PÍCOLO, Guilherme Gouvêa. O direito de morrer: eutanásia, distanásia e ortotanásia no direito comparado. Revista Investidura, Florianópolis - Santa Catarina, ano 4, vol. 18, p. 16-21, mar./abr. 2012. p. 19.

37 PÍCOLO, Guilherme Gouvêa. O direito de morrer: eutanásia, distanásia e ortotanásia no direito comparado. Revista Investidura, Florianópolis - Santa Catarina, ano 4, vol. 18, p. 16-21, mar./abr. 2012. p. 19. 
Aliado a este segundo entendimento, com a criação de um tipo penal próprio para a eutanásia, está o Projeto de Lei 236/12, de autoria do Senador José Sarney, também chamado de Projeto de Novo Código Penal. O texto trata não apenas da conduta da eutanásia, aplicando-Ihe uma pena mais branda, como também inclui em seu parágrafo segundo a exclusão de ilicitude para a ortotanásia ${ }^{38}$ :

Art. 122. Matar, por piedade ou compaixão, paciente em estado terminal, imputável e maior, a seu pedido, para abreviar-lhe sofrimento físico insuportável em razão de doença grave:

Pena de prisão de dois a quatro anos.

$\$ 1^{\circ} \mathrm{O}$ juiz deixará de aplicar a pena avaliando as circunstâncias do caso, bem como a relação de parentesco ou estreitos laços de afeição do agente com a vítima.

$\$ 2^{\circ}$ Não há crime quando o agente deixa de fazer uso de meios artificiais para manter a vida do paciente em caso de doença grave irreversível, e desde que essa circunstância esteja previamente atestada por dois médicos e haja consentimento do paciente, ou, na sua impossibilidade, de ascendente, descendente, cônjuge, companheiro ou irmão.

A tipificação da conduta no Projeto do Novo Código Penal, sem dúvidas, coaduna-se mais com os ordenamentos contemporâneos progressistas do que a postura atual do Código Penal, contudo, se a intenção fora encerrar o debate quanto à eutanásia, a ousadia e, talvez, precipitação, de sua proposta, acaba por gerar uma série de dúvidas quando confrontada com o ordenamento jurídico pátrio: diante da concepção que vem sendo dada pelo Supremo Tribunal Federal à vida, caberia o abrandamento de pena ao agente da conduta? É realmente possível, em conformidade com os princípios fundamentais do país, a excludente de ilicitude à ortotanásia? É a resposta a estes questionamentos que se buscará nos itens que se seguem.

\section{ADI 3.510 E A ABSOLUTIZAÇÃO DA VIDA}

As questões referentes à vida e à morte indubitavelmente estão impregnadas de fatores religiosos, culturais, morais e filosóficos, o que acaba, não somente por acalorar os debates, como também a dificultar a assepsia do trabalho de juristas, uma vez que é impossível demarcar de modo hermético onde se encerra a técnica

38 SOUZA, Ana Victoria de Paula. Algumas considerações acerca das inovações propostas no novo Código Penal. Revista Jurídica UNIGRAN, Dourados - MS, v. 15, n. 29, p. 67-82, jan./jul. 2013. p. 74. 
jurídica e onde se iniciam as concepções pessoais e pré-compreensões de quem julga ou legisla ${ }^{39}$.

Nesse sentido, a fim de facilitar minimamente o debate quanto à vida e sua possível sacralização no direito pátrio, importa aclarar o que este vem entendendo pelo momento da morte. É com a Lei no 9.434/97 e suas alterações trazidas pela Lei nº 10.211/01 que o direito brasileiro vem utilizando as determinações desta quanto ao momento da morte ${ }^{40}$. A referida lei, que dispõe sobre a remoção de tecidos, órgãos e partes do corpo humano para fins de transplante e tratamento fala que:

Art. $3^{\circ}$ A retirada post mortem de tecidos, órgãos ou partes do corpo humano destinados a transplante ou tratamento deverá ser precedida de diagnóstico de morte encefálica, constatada e registrada por dois médicos não participantes das equipes de remoção $e$ transplante, mediante a utilização de critérios clínicos e tecnológicos definidos por resolução do Conselho Federal de Medicina.

Percebe-se, portanto, que a lei, ao tratar da retirada dos tecidos, órgãos ou partes do corpo humano após a morte encefálica autoriza a remoção destes devido à compreensão de que se chegara ao termo final da vida.

Depreende-se, portanto, que para a lei existe morte a partir da cessação plena e não reversível das funções cerebrais. Contrario sensu, entende-se que mesmo não tendo ainda havido a "morte cardíaca", isto é, não tenha ocorrido total parada cárdio-respiratória, ainda que seja ela iminente, a norma legal permite considerar já morto o indivíduo com total ausência das funções encefálicas, após haver sido tal situação devidamente constatada por médicos, na forma estabelecida pela própria lei. ${ }^{41}$.

De modo inverso, possivelmente pela maior diversidade em variados campos e pelas consequências de sua conceituação em temas controversos como o aborto, o início da vida ainda não possui conceituação jurídica, segundo interpretação do Supremo Tribunal Federal, uma vez que "o Magno Texto Federal não dispõe sobre o início da vida humana ou o preciso instante em que ela começa"42.

O debate trazido pela Ação Direta de Inconstitucionalidade n 3.510 de maio de 2005, que trata sobre a constitucionalidade do artigo $5^{\circ}$ da Lei de Biossegurança (n० 11.105/2005), mesmo sem chegar a um consenso quanto ao início da vida

39 STRECK, Lênio Luiz. Hermenêutica Jurídica e(m) Crise - uma exploração hermenêutica da construção do Direito. 10. ed. Porto Alegre: Livraria do Advogado, 2011. p. 328.

40 TAVARES, André Ramos. Curso de direito constitucional. 10. ed. São Paulo: Saraiva, 2012. p. 578.

41 GUIMARÃES, Marcello Ovídio Lopes. Eutanásia - Novas considerações penais. 2008. 360 f. Tese (Doutorado do Departamento de Direito Penal, Medicina Forense e Criminologia) - Faculdade de Direito da Universidade de São Paulo, São Paulo, 2008. p. 56.

42 BRASIL.STF. ADI 3.510/2008, ementa, p. 3. 
- primeiramente tratado como conceito fundamental para o debate e posteriormente descartado pelo plenário -, é rico nas acepções do Supremo Tribunal Federal quanto ao valor da vida dado pela Constituição Federal de 1988, assim também como da dignidade da pessoa humana e mesmo da autonomia dos indivíduos, sendo ponto fulcral para a interpretação da possibilidade de eutanásia no país.

$\mathrm{O}$ artigo posto em cheque quanto à sua constitucionalidade trata da utilização de células tronco-embrionárias de embriões in vitro, os quais serão descartados pelos doadores do material genético. Com um resultado de seis votos favoráveis à constitucionalidade do artigo contra cinco parcialmente desfavoráveis, percebem-se nos votos dos ministros uma pluralidade de concepções quanto à vida e sua inviolabilidade.

Como aponta a professora Naara Luna ${ }^{43}$, nos votos dos ministros Carlos Ayres Britto, Carmen Lúcia e Ricardo Lewandowiski a argumentação quanto à inviolabilidade da vida, assim como a referência à Declaração da UNESCO sobre Genoma Humano e sua proposição quanto à intangibilidade do material genético, acabam por sacralizar a natureza biológica, apontando o indivíduo como valor. Tal aproximação entre o sagrado e o direito se vê de forma nítida nos dizeres do ministro Carlos Britto, segundo o qual o "sagrado na religião corresponde ao inviolável no direito"44.

Em contrapartida, observam-se nos votos vencedores dos ministros Celso de Mello, Joaquim Barbosa, assim como do ministro Gilmar Mendes, argumentações relevantes quanto à não absolutização do direito à vida e as dimensões da dignidade da pessoa humana e da autonomia em seus entendimentos.

Como bem clarificado na ementa do acórdão supra, preza-se, na visão do ministro Celso de Mello, por uma dimensão da vida baseada na solidariedade, compaixão e fraternidade, uma vez que:

[...] longe de traduzir desprezo ou desrespeito aos congelados embriões "in vitro", significa apreço e reverência a criaturas humanas que sofrem e se desprezam. Inexistência de ofensas ao direito à vida e da dignidade da pessoa humana, pois a pesquisa com células tronco-embrionárias (inviáveis biologicamente ou para os fins a que se destinam) significa a celebração solidária da vida e alento aos que se acham à margem do exercício concreto e inalienável dos direitos à felicidade e do viver com dignidade. ${ }^{45}$

É nítido que a percepção de solidariedade e da busca de alento aos que vivem à margem do exercício concreto dos direitos de felicidade e de viver com dignidade mais se aproxima de um paradigma beneficente, da eutanásia voluntária, ou seja, a

43 LUNA, Naara. O direito à vida no contexto do aborto e da pesquisa com células-tronco embrionárias: disputas de agentes e valores religiosos em um estado laico. Revista Religião e Sociedade, v. 33, n. 1, p. 71-97, 2013. p. 81.

44 BRASIL. STF. ADI 3.510/2008, Voto Ministro Carlos Britto, p. 28.

45 BRASIL.STF.ADI 3.510/2008, ementa, p. 3. 
pacientes que não se consideram detentores de uma vida digna e solicitam a prática, do que a extensão da vida para além da vontade de quem sofre, como na distanásia.

Nesse mesmo sentido, o ministro Joaquim Barbosa é literal em seu voto quanto ao caráter não absoluto do direito à vida:

[...] segundo nosso ordenamento jurídico o direito à vida e a tutela do direito à vida são dois aspectos de um mesmo direito, o qual, como todo direito fundamental, não é absoluto, nem hierarquicamente superior a qualquer outro direito fundamental. ${ }^{46}$

Por fim, cabe ainda trazer à baila os dizeres de Gilmar Ferreira Mendes, que ao considerar temas como aborto, eutanásia e utilização de embriões humanos para fins de pesquisa como "tarefas que transcendem os limites do jurídico e envolvem argumentos da moral, política e religião" 47 , aborda a necessidade de utilização do princípio da responsabilidade estatal frente a decisões de tamanha complexidade, aduzindo que:

A dimensão objetiva dos direitos fundamentais legitima a idéia de que o Estado se obriga não apenas a observar os direitos de qualquer indivíduo em face das investidas do Poder Público (direito fundamental enquanto direito de proteção ou de defesa - Abwehrrecht), mas também a garantir os direitos fundamentais contra agressão propiciada por terceiros (Schutzpflicht des Staats). ${ }^{48}$

Ora, imputar pena a profissionais da saúde que não prolonguem a vida por meios artificiais de pacientes terminais é, a contrario sensu, incentivá-los a ignorar a vontade dos doentes, inclusive com intervenções corporais contra suas vontades, nítidas agressões físicas e também psicológicas.

É nesse diapasão que afirmam Luís Roberto Barroso e Letícia de Campos Velho Martel ${ }^{49}$ quanto à jurisprudência do STF a existência das seguintes formulações recorrentes do tribunal, as quais figuram como consensos sobrepostos, ou seja, pontos de consenso político aceitos por indivíduos ou grupos que não partilham as mesmas crenças. São eles: a não instrumentalização dos seres humanos, da liberdade humana e das garantias constitucionais da liberdade; a preservação da integridade física e moral dos indivíduos; e a proibição da tortura, da imposição de tratamento desumano ou degradante e da crueldade.

A fim de exemplificação dos consensos acima expostos, cabe mencionar a proibição da redução de ser humano à condição análoga a de escravo quanto à garantia

\footnotetext{
46 BRASIL. STF. ADI 3.510/2008, voto ministro Joaquim Barbosa, p. 2.

47 BRASIL. STF. ADI 3.510/2008, voto Ministro Gilmar Ferreira Mendes, p.2.

48 BRASIL. STF. ADI 3.510/2008, Voto Min. Gilmar Mendes, p. 12.

49 BARROSO, Luís Roberto; MARTEL, Letícia de Campos Velho. A morte como ela é: dignidade e autonomia individual no final da vida. Revista da Faculdade de Direito da Universidade Federal de Uberlândia, São Paulo, v. 34, n. 1, p. 235-274, 2010 p. 30.
} 
constitucional de liberdade e da não instrumentalização do ser humano ${ }^{50}$; a impossibilidade de realização de exame de DNA compulsório para comprovação de paternidade como leading case da preservação da integridade física ${ }^{51}$; assim como do crime de tortura contra crianças e adolescentes ${ }^{52}$.

Ocorre que, diante de tal concepção, cabe, ainda, a questão: seria a Corte Constitucional Brasileira - Supremo Tribunal Federal - o guardião da constituição e, portanto, aquele que deve dar tal interpretação ao texto constitucional? Ou estaria o Tribunal indo além de sua função e superando, de modo ilegítimo, as atribuições do legislador pátrio, aquele efetivamente votado pelo povo?

Faz-se indubitável a percepção de que, frente ao neoconstitucionalismo vivido pelo direito contemporâneo, a força da jurisprudência e, consequentemente, a centralidade adquirida pelo Poder Judiciário diante da crise de representatividade do Poder Legislativo em várias nações ${ }^{53}$, como a brasileira, reforçam a percepção de que, sim, o Supremo Tribunal Federal apresenta-se como legítimo para tal interpretação constitucional.

Nesse aspecto, Cynara Monteiro Mariano, explicita o deslocamento de preponderância qualitativa do Legislativo ao Judiciário:

[...] É preciso que se diga que uma das causas, talvez a maior de todas, que influenciaram a expansão da jurisdição constitucional foi a perda paulatina de efetividade do processo político em virtude das omissões do próprio Legislativo no desempenho de suas funções, que são ofuscadas pela preponderância dos vícios intrínsecos às lutas partidárias pela continuidade no poder, enquanto que as questões políticas e jurídicas que interessam ao povo ficam em segundo plano. Assim, a razão pela qual o Legislativo tenha perdido terreno na tarefa de concretizar os direitos fundamentais é justamente o distanciamento da classe política do povo e o seu enclausuramento, cada vez mais notório, às disputas internas de poder.

É, pois, na fase atual do direito, marcada pela complexidade social e dinamicidade de tais relações, que a contribuição do legislador ao direito faz-se apenas de modo parcial, cabendo mais aos juízes, em contato constante com o caso concreto, valorar e interpretar a conformidade de sua sentença ao texto constitucional ${ }^{54}$.

50 BRASIL. STF. HC n०92.604-5/SP. Rel. Min. Gilmar Mendes. 25/04/2008.

51 BRASIL. STF. HC n71.373-4/RS. 22/11/1996.

52 BRASIL. STF. HC n070.389-5 /SP. 10/08/2001.

53 LOSURDO, Federico. O guardião da Constituição e a crise institucional brasileira. In: CARVALHO, Márcia Haydée Porto de, FIGUEIREDO, Marcelo (Orgs.). Direitos Fundamentais, Pluralismo e Democracia na Jurisprudência do Supremo Tribunal Federal, São Luís: UFMA, 2017. p. 9.

54 ZAGREBELSKI, Gustavo. El derecho dúctil - Ley, derecho, justicia. Madrid: Editorial Trotta, 2011. p. 150. 
Acaba por recair aos juízes, e à Corte Constitucional como sua máxima expressão, a guarda do texto constitucional, não como letra estática, mas com uma interpretação que consiga, diante da situação concreta, fazer a coexistência entre a lei, o direito e a justiça, como bem leciona Gustavo Zagrebelski ${ }^{55}$ :

Hoy, ciertamente, los jueces tienen uma gran responsabilidade em la vida del derecho desconocida en los ordenamientos del Estado de derecho legislativo. Pero los jueces no son los señores del derecho em el mismo sentido en que lo era el legislador em el passado siglo. Son más exatamente los garantes de la complejidad estructural del derecho en el Estado constitucional, es decir, los garantes de la necessária y dúctil coexistencia entre ley, derecho y justicia. ${ }^{56}$

Diante disso que se coaduna a possibilidade do Supremo Tribunal Federal, enquanto Corte Constitucional pátria, em realizar interpretações valorativas do texto constitucional, a exemplo do valor à vida e mesmo dignidade da pessoa humana, analisadas no presente trabalho. Perceba-se, que, o que se apresenta nestas breves linhas não é a advocacia de supremacia do Poder Judiciário frente ao Legislativo, apenas uma análise de que, diante da crise de representatividade deste último em relação aos anseios populares, acabam por, no mundo prático, recair determinados casos de grande anseio popular às mãos do Judiciário, o qual não se pode negar a responder às demandas que lhe são colocadas.

Superado este ponto, o que propõe é o estudo sobre a possibilidade ou não de autorização da eutanásia no país, frente a uma interpretação conforme a Constituição Federal de 1988 e balizado pelas valorações aos princípios fundamentais dadas pela Corte Constitucional.

\section{EUTANÁSIA: ENTRE A DIGNIDADE DA PESSOA HUMANA E O DI- REITO À VIDA SOB A CONSTITUIÇÃO FEDERAL DE 1988}

$\mathrm{Na}$ atual fase da normatividade dos ordenamentos, pós-positivista, a reaproximação entre direito e moral acentua o caráter valorativo das jurisprudências. Não apenas, é nesta fase que os princípios, agora positivados nos textos constitucionais, adquirem caráter basilar e axiológico de todo o sistema jurídico. ${ }^{57}$

Considerados normas jurídicas, assim como as regras, os princípios também se formulam por expressões deônticas fundamentais, sendo neste caso mandados ou mandamentos de otimização. Em outras palavras, enquanto as normas jurídicas do tipo

\footnotetext{
55 ZAGREBELSKI, Gustavo. El derecho dúctil - Ley, derecho, justicia. Madrid: Editorial Trotta, 2011. p. 153.

56 ZAGREBELSKI, Gustavo. El derecho dúctil - Ley, derecho, justicia. Madrid: Editorial Trotta, 2011. p. 153.

57 SARMENTO, Daniel. Direito Constitucional - Teoria, história e métodos de trabalho. Belo Horizonte: Editora Fórum, 2012. p. 306.
} 
regras são determinações, definitivas, no plano fático e diante do que é juridicamente possível, devendo ou ser aplicadas ou abandonadas e substituídas por outra que meIhor se subsuma ao caso concreto, os princípios realizam-se na maior medida possível, podendo, inclusive, ser aplicados em graus distintos a depender da situação real ${ }^{58}$.

Nesse sentido, é clara a lição de Paulo Bonavides ${ }^{59}$ :

[...] Uma diferença separa a norma legal da norma principial: a primeira é uma norma desenvolvida em seu conteúdo e precisa em sua normatividade: acolhe e perfila os pressupostos de sua aplicação, determina com detalhe o seu mandato, estabelece possíveis exceções; o princípio, pelo contrário, expressa a imediata e não desenvolvida derivação normativa dos valores jurídicos: seu pressuposto é sumamente geral e seu conteúdo normativo é tão evidente em sua justificação como inconcreto em sua aplicação. É aqui que o princípio, ainda quando legalmente formulado, continua sendo princípio, necessitado por isso de desenvolvimento legal e de determinação casuística em sua aplicação judicial. ${ }^{60}$

Ora, elencados a status constitucional e diante da hierarquia deste texto em relação às demais normas dos ordenamentos jurídicos, os princípios passam a encabeçar o sistema, influenciando e fundamentando a construção e interpretação das demais normas $^{61}$. É nesse sentido que analisar a constitucionalidade da não imputação de pena a agentes da eutanásia, assim também como do possível acerto ou erro do Projeto de Lei no 326/12 (Novo CP) frente ao sistema jurídico pátrio, necessita, indubitavelmente, da percepção quanto aos princípios fundamentais da vida e dignidade da pessoa humana positivados na Constituição Federal de 1988.

Inicialmente quanto à vida, a mesma encontra-se no caput do artigo $5^{\circ} \mathrm{da} C F-$ 88, constando a inviolabilidade da mesma enquanto um direito fundamental. Tal direito, segundo entendimento de André Ramos Tavares ${ }^{62}$, pode ser traduzido em duas vertentes: o direito ao indivíduo permanecer existente e o direito a um nível de vida adequado.

É nesse último ponto que repousa a tese favorável à eutanásia. Quando conflitadas ambas as esferas do direito à vida, como nos casos de solicitação da morte piedosa, é inegável que a insistência no permanecer vivo aos que desejam morrer acoima o referido nível de vida adequado. É, portanto, quando o exercício do direito de

\footnotetext{
58 ALEXY, Robert. Teoria de los derechos fundamentales. Madrid: Centro de Estudios Constitucionales, 1993. p. 86.

59 BONAVIDES, Paulo. Curso de Direito Constitucional. 16. ed. São Paulo: Malheiros, 2005. p. 291.

60 BONAVIDES, Paulo. Curso de Direito Constitucional. 16. ed. São Paulo: Malheiros, 2005. p. 291.

61 BONAVIDES, Paulo. Curso de Direito Constitucional. 16. ed. São Paulo: Malheiros, 2005. p. 292.

62 TAVARES, André Ramos. Curso de direito constitucional. 10. ed. São Paulo: Saraiva, 2012. p. 575.
} 
viver esbarra na vida adequada, ou seja, minimamente digna, que vale questionar se viver é um direito ou passa a ser um dever do cidadão.

Entende-se a dignidade da pessoa humana como:

[...] a qualidade intrínseca e distintiva de cada ser humano que o faz merecedor do mesmo respeito e consideração por parte do Estado e da comunidade, implicando, neste sentido, um complexo de direitos e deveres fundamentais que assegurem a pessoa tanto contra todo e qualquer ato de cunho degradante e desumano, como venham a lhe garantir as condições existenciais mínimas para uma vida saudável, além de propiciar e promover sua participação ativa e co-responsável nos destinos da própria existência e da vida em comunhão com os demais seres humanos. ${ }^{63}$

É nesse diapasão que a positivação da dignidade da pessoa huamana na CF-88, artigo $1^{\circ}$, inciso III, a transforma em norma de valoração base aos demais direitos fundamentais. Ademais, coadunando-se com o entendimento do ministro Joaquim Barbosa em seu voto na ADI $3.510^{64}$, deve-se compreender que assim como a Constituição tutela a vida, trata igualmente enquanto direito fundamental a inviolabilidade da liberdade - artigo $5^{\circ}$, caput.

Há que se entender nesse ponto que a dita liberdade não possui apenas uma faceta positiva, mas também um caráter negativo, como ensina Norberto Bobbio ${ }^{65}$ :"Por 'libertad negativa' se entiende, em el linguaje político, la situación en la cual um sujeto tiene la possibilidade de obrar o de no obrar, sin ser obligado a ello o sin que se lo impidan otros sujetos."

Ora, é em face da equiparação do direito à vida aos demais direitos fundamentais que não cabe ao Estado impedir ao indivíduo a liberdade de renunciar ao viver quando tal condição Ihe implica degradação física ou psicológica, uma vez que:

[...] a renúncia é também uma forma de exercício do direito fundamental, dado que, por um lado, a realização de um direito fundamental inclui, em alguma medida, a possibilidade de se dispor dele, inclusive no sentido de sua limitação, desde que esta seja uma expressão genuína do direito de autodeterminação e livre desenvolvimento da personalidade individual, e porque, por outro lado, através da renúncia o indivíduo prossegue a realização de fins e interesses próprios que ele considera, no caso concreto, mais relevantes que os fins realizáveis através de um exercício positivo do direito. ${ }^{66}$

\footnotetext{
63 SARLET, Ingo Wolfgand. Dignidade da Pessoa Humana e Direitos Fundamentais na Constituição Federal de 1988. Porto Alegre: Livraria do Advogado, 2001. p. 60.

64 BRASIL. STF. ADI 3.510/2008, voto ministro Joaquim Barbosa, p. 2.

65 BOBBIO, Norberto. Igualdad y Libertad. Barcelona: Paidós I.C.E./U.A.B, 1993. p. 97.

66 NOVAIS, Jorge Reis. Direitos Fundamentais: Trunfos contra a maioria. Coimbra: Coimbra Editora, 2006. p. 235.
} 
Uma vez que o atual Código Penal não explicita a conduta de eutanásia e vêse presente a polissemia quanto a sua criminalização no ordenamento pátrio, cabe a utilização do princípio da interpretação conforme a constituição a fim de se obter um entendimento unívoco no homicídio piedoso, resguardando profissionais da saúde, parentes e pacientes.

Utilizado enquanto uma forma de controle de constitucionalidade interpretativa ${ }^{67}$, o princípio da interpretação conforme assegura um entendimento de determinada norma infraconstitucional em obediência ao sistema axiológico presente no texto constitucional.

É diante da análise supra quanto à possibilidade de se renunciar a um direito fundamental, assim também da equiparação entre vida e liberdade e do caráter basilar da dignidade da pessoa humana dado pelo ordenamento que, fazendo-se uma interpretação conforme a CF-88, é nítida a inconstitucionalidade presente na analogia jurisdicional entre o homicídio piedoso e o homicídio privilegiado, posto que naquele prevalecem a benignidade, a liberdade negativa do paciente em renunciar à vida, assim também como o paradigma da fraternidade, o que não ocorre em um homicídio egoístico motivado por valores morais ou fortes emoções.

A tipificação da conduta no projeto do Novo CP e a imputação de pena, mesmo que mais branda, seguem a mesma linha de inconstitucionalidade acima analisada, ressaltando-se, contudo, o acerto do mesmo em não criminalizar a ortotanásia.

\section{CONSIDERAÇÕES FINAIS}

É perceptível que a boa morte, o homicídio eutanásico, deve se ver libertado das acepções pejorativas que recebeu em meados do século $X X$, uma vez que diferentemente dos extermínios eugênicos, cujo ápice fora percebido na Segunda Guerra Mundial com as práticas nazistas, a conduta é movida pela compaixão, a fim de libertar o indivíduo, por meio de ação ou omissão, de sofrimento físico ou psíquico que o mesmo considere insuperável.

Nesse sentido, percebendo-se a interpretação dada pelo Supremo Tribunal Federal ao direito fundamental à vida quando do julgamento da ADI 3.510, passa-se a compreender a mesma não apenas enquanto um direito a permanecer vivo, como também, baseado pela fraternidade, um direito a viver de modo adequado, sendo o mesmo equiparado a todos os demais direitos fundamentais positivados na CF-88 e, portanto, passível de renunciabilidade.

Diante disso, considerando-se a dignidade da pessoa humana enquanto valor basilar aos demais direitos e deveres fundamentais e a faceta negativa da liberdade individual, que se apreende a possibilidade, em uma interpretação conforme a

67 CANOTILHO, J.J. Gomes. Direito Constitucional. 6 ed. rev. Coimbra: Livraria Almedina, 1993. p. 229. 
constituição, de não imputação de pena ao agente da conduta de eutanásia. Observese que a vida é renunciável e cabe ao sujeito detentor do direito decidir em continuar o curso natural da morte ou permitir a obstinação terapêutica, o que não vem sendo aplicado nos hospitais do país, posto que, temendo imputação penal caso não insistam no tratamento de paciente terminal, os médicos, inclusive contra a vontade do sujeito, insistem em tratá-lo.

Nesse diapasão e diante do caráter de controle de constitucionalidade presente no princípio da interpretação conforme, se vê a inconstitucionalidade em tratar de modo igualitário o homicídio privilegiado, como vem acontecendo na prática judiciária brasileira, e a conduta eutanásica.

Do mesmo modo, o legislador infraconstitucional equivoca-se no Projeto de Lei n 236/12, Novo Código Penal, ao imputar pena ao agente do homicídio eutanásico, legislando conforme a Constituição Federal apenas no parágrafo $2^{\circ}$ do artigo 122 do mesmo projeto, posto que isenta de pena o praticante da ortotanásia.

Por fim, cabe ressaltar que tal qual acontecido na maioria dos países que despenalizaram a conduta, a exemplo da Colômbia, se faz necessário um amplo debate político, a fim de que o texto que trate sobre a despenalização da eutanásia disponha de modo claro sobre os requisitos necessários para a comprovação da motivação beneficente da conduta, como no Uruguai, de modo a possibilitar o resguardo tanto dos direitos fundamentais à vida, quanto a liberdade e dignidade da pessoa humana.

\section{REFERÊNCIAS}

ALEXY, Robert. Teoria de los derechos fundamentales. Madrid: Centro de Estudios Constitucionales, 1993.

ASUA, Luis Jimenez de. Libertad de Amar y Derecho a Morrir - ensayos de un criminalista sobre eugenesia, eutanasia, endocrinologia. Madrid: Historia Nueva, 1929.

ARZAMENDI, José Luis de La Cuesta. A eutanásia no direito comparado. Revista Jurídica Consulex, São Paulo, ano V, n. 114, out. 2001.

BOBBIO, Norberto. Igualdad y Libertad. Barcelona: Paidós I.C.E./U.A.B, 1993.

DIAS, Roberto. Disponibilidade do Direito à vida e Eutanásia. Revista da Faculdade de Direito de São Bernardo do Campo, São Paulo, ano 14, n. 16, p. 182-206, 2010.

BONAVIDES, Paulo. Curso de Direito Constitucional. 16. ed. São Paulo: Malheiros, 2005.

BARROSO, Luís Roberto; MARTEL, Letícia de Campos Velho. A morte como ela é: dignidade e autonomia individual no final da vida. Revista da Faculdade de Direito da Universidade Federal de Uberlândia, São Paulo, v. 34, n. 1, p. 235-274, 2010. 
COLOMBIA. Corte Constitucional Colombiana. Ementa sentença 329/97. Demanda de inconstitucionalidade contra o artigo 326 do decreto 100 de 1980-Código Penal. Demandante: José Eurípides Parra Parra. Magistrado Proponente: Dr. Carlos Gaviria Diaz, 1997.

CANOTILHO, J.J. Gomes. Direito Constitucional. 6 ed. rev. Coimbra: Livraria Almedina, 1993.

DINIZ, Débora. A despenalização da eutanásia passiva: o caso colombiano. SérieAnis, Brasília, n.13, Letras Livres, p. 1-3, 2000.

DINIZ, Débora; COSTA, Sérgio. Morrer com dignidade: um direito fundamental. In: CAMARANO, Ana Amélia. Os Novos Idosos Brasileiros: Muito Além dos 60. Rio de Janeiro: IPEA, 2004. p. 121-134.

DWORKIN, Ronald. Domínio da Vida - Aborto, eutanásia e liberdades individuais. São Paulo: Martins Fontes, 2003.

GOLDIM, José Roberto. Breve histórico da eutanásia. Núcleo Interinstitucional de Bioética - UFRGS, 2000. Disponível em: <https://www.ufrgs.br/bioetica/euthist.htm>. Acesso em: 13 de jul. de 2016.

GOLDIM, José Roberto. Eutanásia - Uruguai. Núcleo Interinstitucional de Bioética - UFRGS, 1997. Disponível em: <https://www.ufrgs.br/bioetica/eutanuru.htm>. Acesso em: 13 de jul. de 2016.

GUIMARÃES, Marcello Ovídio Lopes. Eutanásia - Novas considerações penais. 2008. 360 f. Tese (Doutorado do Departamento de Direito Penal, Medicina Forense e Criminologia) - Faculdade de Direito da Universidade de São Paulo, São Paulo, 2008.

LOSURDO, Federico. O guardião da Constituição e a crise institucional brasileira. In: CARVALHO, Márcia Haydée Porto de, FIGUEIREDO, Marcelo (Orgs.). Direitos Fundamentais, Pluralismo e Democracia na Jurisprudência do Supremo Tribunal Federal, São Luís: UFMA, 2017.

LUNA, Naara. O direito à vida no contexto do aborto e da pesquisa com células-tronco embrionárias: disputas de agentes e valores religiosos em um estado laico. Revista Religião e Sociedade, v. 33, n. 1, p. 71-97, 2013.

MARTIN, Leonard M. Eutanásia e Distanásia. In: COSTA, Sérgio Ibiapina; GARRAFA, Volnei; OSELKA, Gabriel. (Orgs). Iniciação à Bioética. Brasília: Conselho Federal de Medicina, 1998. p. 171-192.

MCCONNELL, Terrance. Inalienable rights: the limits of consent in medicine and the law. Oxford: Oxford University, 2000.

MENEGAT, Carla. Os pensadores que influenciaram a política de eugenia do nazismo. Revista A MARgem, Uberlândia, Minas Gerais, ano 1, n. 2, p. 66-73, jul./dez. 2008.

NOVAIS, Jorge Reis. Direitos Fundamentais: Trunfos contra a maioria. Coimbra: Coimbra Editora, 2006. 
SANTANA, Júlio César Batista; RIGUEIRA, Ana Cláudia de Melo; DUTRA, Bianca Santana. Distanásia: reflexões sobre até quando prolongar a vida em uma Unidade de Terapia Intensiva na percepção dos enfermeiros. Revista Bioethikos, Minas Gerais, Centro Universitário São Camilo, ano 4, vol. 4, 2010. p. 402-411.

SARLET, Ingo Wolfgand. Dignidade da Pessoa Humana e Direitos Fundamentais na Constituição Federal de 1988. Porto Alegre: Livraria do Advogado, 2001.

SARMENTO, Daniel. Direito Constitucional - Teoria, história e métodos de trabalho. Belo Horizonte: Editora Fórum, 2012.

SOUZA, Ana Victoria de Paula. Algumas considerações acerca das inovações propostas no novo Código Penal. Revista Jurídica UNIGRAN, Dourados - MS, v. 15, n. 29, p. 67-82, jan./jul. 2013.

STRECK, Lênio Luiz. Hermenêutica Jurídica e(m) Crise - uma exploração hermenêutica da construção do Direito. 10. ed. Porto Alegre: Livraria do Advogado, 2011.

TAVARES, André Ramos. Curso de direito constitucional. 10. ed. São Paulo: Saraiva, 2012.

PíCOLO, Guilherme Gouvêa. O direito de morrer: eutanásia, distanásia e ortotanásia no direito comparado. Revista Investidura, Florianópolis - Santa Catarina, ano 4, vol. 18, p. 16-21, mar./ abr. 2012.

ZAGREBELSKI, Gustavo. El derecho dúctil - Ley, derecho, justicia. Madrid: Editorial Trotta, 2011. 